GRASAS Y ACEITES, 63 (1), ENERO-MARZO, 53-60, 2012, ISSN: 0017-3495 DoI: $10.3989 /$ gya.033311

\title{
Quantification of rice bran oil in oil blends
}

\author{
By R. Mishra*, H.K. Sharma and G. Sengar
}

Food Engineering and Technology Department. Sant Longowal Institute of Engineering \& Technology (Deemed to be University) Longowal - 148 106. Sangrur (PUNJAB). INDIA

${ }^{*}$ Corresponding author: richa.ft2003@gmail.com

\section{RESUMEN}

Cuantificación de aceite de salvado de arroz en mezclas de aceites.

Se analizaron diversos parámetros físico-químicos para la evaluación de mezclas de aceites en diferentes proporciones que incluyen: aceite de salvado de arroz físícamente refinado (PRBO): aceite de girasol (SNF) y las mezclas PRBO: aceite de cártamo (SAF) en diferentes proporciones. La cuantificación de la presencia del aceite de salvado de arroz en las mezclas se llevó a cabo por diferentes métodos, como cromatografía de gases (GC), cromatografía líquida (HPLC), ultrasonidos y métodos basados en otros parámetros físico-químicos. Los parámetros físico-químicos como la velocidad de ultrasonidos, la asociación y la impedancia acústica a $2 \mathrm{MHz}$, el índice de yodo, el contenido en ácido palmítico y el contenido de orizanol reflejan cambios significativos con el aumento de la proporción de PRBO en las mezclas de aceites. Estos parámetros fueron seleccionados como parámetros dependientes y las proporciones de PRBO fue seleccionado como parámetro independiente. El estudio reveló que las ecuaciones de regresión basadas en el contenido de orizanol, la composición de ácido palmítico, la velocidad de ultrasonidos, la asociación relativa, la impedancia acústica, y el índice de yodo pueden ser utilizados para la cuantificación de aceite de salvado de arroz en las mezclas de aceites. El aceite de salvado de arroz puede ser cuantificado en las mezclas de aceites mediante el contenido orizanol determinado por HPLC, incluso a nivel de $1 \%$. El contenido de ácido palmítico en los aceites de mezcla también se puede utilizar como un indicador para cuantificar el aceite de salvado de arroz en $20 \%$ o más nivel en los aceites de mezcla, donde el método basado en la velocidad ultrasónica, la impedancia acústica y de asociación relativa parecía prometer inicialmente en la cuantificación de arroz aceite de salvado.

PALABRAS CLAVE: Cuantificación de aceite de salvado de arroz - HPLC - Orizanol - Velocidad ultrasonidos.

\section{SUMMARY}

\section{Quantification of rice bran oil in oil blends.}

Blends consisting of physically refined rice bran oil (PRBO): sunflower oil (SnF) and PRBO: safflower oil (SAF) in different proportions were analyzed for various physicochemical parameters. The quantification of pure rice bran oil in the blended oils was carried out using different methods including gas chromatographic, HPLC, ultrasonic velocity and methods based on physico-chemical parameters. The physicochemical parameters such as ultrasonic velocity, relative association and acoustic impedance at $2 \mathrm{MHz}$, iodine value, palmitic acid content and oryzanol content reflected significant changes with increased proportions of PRBO in the blended oils. These parameters were selected as dependent parameters and \% PRBO proportion was selected as independent parameters. The study revealed that regression equations based on the oryzanol content, palmitic acid composition, ultrasonic velocity, relative association, acoustic impedance, and iodine value can be used for the quantification of rice bran oil in blended oils. The rice bran oil can easily be quantified in the blended oils based on the oryzanol content by HPLC even at a $1 \%$ level. The palmitic acid content in blended oils can also be used as an indicator to quantify rice bran oil at or above the $20 \%$ level in blended oils whereas the method based on ultrasonic velocity, acoustic impedance and relative association showed initial promise in the quantification of rice bran oil.

KEY-WORDS: HPLC - Oryzanol - Rice bran oil quantification - Ultrasonic velocity.

\section{INTRODUCTION}

There are varieties of oils which are refined worldwide and some of the oils are being blended due to the current trends in globalization and demand for nutritional enrichment. Blended oils are gaining popularity worldwide due to the advantages they offer such as improved thermal stability, oxidative stability, nutritional benefits (Sharma et al., 1996) and an ability fulfill specific desired properties. Indian food regulations do not permit the addition to vegetable oils of health-promoting components (e.g. oryzanol, tocotrienols and lignan antioxidants) in the form of concentrates and isolates. However, vegetable oils containing such components can be blended with those that do not have such health promoting components. Different branches of the food processing industry have diverse requirements for blended oils and fat products. Frankel and Huang (1994) reported that mixing different proportions of high-oleic sunflower oil (HOSO) with polyunsaturated vegetable oils provides a simple method for preparing more stable edible oils with a wide range of desired 
fatty acid compositions. The fatty acid absorption of a sunflower and canola blend at 7:3, 5:5 was found to be superior to that of unblended oils (Crick et al., 1988). Blended oils have been reported to have better thermal stability; Handoo et al., (1992) reported that groundnut oil and cotton seed oil blends of 50:50 are more stable than pure cotton seed oil. Lower peroxide values were reported in stored food items which were fried in rapeseed-cottonseed blends compared to those fried in groundnut-cottonseed and groundnut-rapeseed oil blends (Mehta et al., 1986). Comparative studies on the physical properties of vegetables oils and their blends after frying indicated a reduction in peroxide value when using blended oils (Susheelamma et al., 2002).

Several researchers have worked on the stability of rice bran oil and its blend with other oils like groundnut oil, sunflower oil, mustard oil etc. which concluded that oil blends showed good stability (Shiela et al., 2004, Sharma et al., 2006). Various methods have been reported for the detection of oil. Ambadi oil was detected in various common edible oils like groundnut, cottonseed, mustard, sunflower, safflower, palm and coconut oil by means of color reaction and spectrophotometry (Adhikari and Adhikari, 1992). A simple TLC method was reported to detect the presence of watermelon seed oil in groundnut and sesame oils. Data (1981) has detected some admixtures such as rapeseed in mustard oil by using critical solution temperature. Seetharamaiah and Prabhakar (1986) also detected the rice bran oil content in other edible vegetable oils by the isolation of oryzanol in rice through TLC. In blends of groundnut-palm and coconut-groundnut oil, quantification of individual oils was achieved on the basis of a computed linear regression equation based on Bellier temperature, cloud point and the fatty acid composition of triglycerides (Sharma et al., 1999). Crude rice bran has been successfully identified and isolated using reversephase HPLC by Xu and Godber, 1999.

The various advantages of blended oils and their increased market demand have also raised the need for a rapid and simple technique for quantifying the proportion of a specific oil in a blend. Therefore, the present study deals with the quantification of pure rice bran oil in the blended oils using different methods.

\section{MATERIALS AND METHODS}

\subsection{Materials}

The oils used in the present investigation (physically refined rice bran oil, sunflower oil and safflower oil) were obtained from A. P. Organics Pvt. Ltd. Dhuri, Punjab. All the solvents and chemicals used for the present study were of AR grade.

\subsection{Preparation of samples}

A pure rice bran oil sample was blended with pure safflower and sunflower oil in different ratios i.e. $1,3,4,5,10$ and $20 \%$ using a high speed homogenized mixer.

\subsection{Analysis of the samples}

lodine value (IV) [Cd 1-25], saponificataion value (SV) [Cd 3-25], refractive index (RI) [Cc 7-25] and specific gravity [Cc 10a-25] were determined using standard methods (AOCS 2004). Oryzanol value (IICT 2008) was measured with a Spectrophotometer (UV-1700, SHIMAZDU). The oryzanol content of each sample was determined by measuring the optical density of the sample at $315 \mathrm{~nm}$ in $\mathrm{n}$-Heptane in a $1 \mathrm{~cm}$ cell using a spectrophotometer.

The fatty acids of triglycerides were analyzed by preparing methyl esters according to a conventional procedure consisting of saponification followed by acidification and finally methylation using diazomethane according to the reported method (Orthoefer and Smith., 1996). A gas chromatographic (GC) analysis of fatty acid methyl esters was carried out using a NUCON SERIES 5700 of data station in the range of $0-2.5 \mathrm{mV}$ with a $<1.5 \mathrm{~s}$ response rate. A $2 \mathrm{~m} \times 2 \mathrm{~mm}$ stainless steel $10 \%$ Silar 7C column packed with 60-120 mesh Gas Chrom $Q$ was used. The injector and detector temperatures were maintained at $240{ }^{\circ} \mathrm{C}$. The column temperature was set at $160{ }^{\circ} \mathrm{C}$ for 5 min and then increased at a rate of $5^{\circ} \mathrm{C}$ per min to a final temperature of $220{ }^{\circ} \mathrm{C}$ and kept there for 20 $\mathrm{min}$. The total time for analysis was $37 \mathrm{~min}$. Fatty acids were tentatively identified by comparison with the retention times of authentic reference samples.

\subsection{Measurement of ultrasonic velocity, relative association acoustic impedance, and compressibility in blended oils}

The densities of all oil samples were measured using a single capillary pycnometer. The measured densities were reproducible within $\pm 0.2 \mathrm{~kg} \mathrm{~m}^{-3}$. The ultrasonic velocities were measured at room temperature $\left(26 \pm 1{ }^{\circ} \mathrm{C}\right)$ using a single crystal variable-path interferometer at 1 and $2 \mathrm{MHz}$ with an accuracy of $\pm 0.05 \%$. The criteria of purities of chemicals and accuracies were checked by comparing the experimental values with a distilled water sample. The isotropic compressibility, relative association, acoustic impedance and adiabatic compressibility were calculated using equations 1, 2, 3 and 4 respectively (Mehra and Israni., 1999).

$$
\begin{aligned}
& \mathrm{Ks}=u^{-2} \rho^{-1} \\
& \mathrm{RA}=\left(\rho^{0} \rho^{0}\right)\left(u^{0} / u\right)^{1 / 3} \\
& Z=u \rho \\
& \beta=1 /\left(u^{0}\right)^{2} \rho^{0}
\end{aligned}
$$


Ks isotropic compressibility: $\rho^{0}$ densities of control sample: $U^{0}$ ultrasonic velocity of control sample: $R A$ relative association: $Z$ acoustic impedance: $\beta$ adiabatic compressibility: $\rho$ density of sample: $u$ ultrasonic velocity of sample.

\subsection{Oryzanol estimation by HPLC}

The oryzanol content (CD13CS-11) was estimated according to the standard method (AOCS 2004). The estimation was carried out using an HPLC system of Agilent technologies, connected to an injector with a $20 \mu \mathrm{L}$ sample loop. The sample was weighed to $5 \mathrm{~g}$ and transferred to a $50 \mathrm{~mL}$ volumetric flask and the volume was made up with $\mathrm{n}$-hexane. Then the solution was filtered through a $0.45 \mu \mathrm{m}$ filter. The filtered sample was used for HPLC analysis.

The sample, $20 \mu \mathrm{L}$, was injected into an HPLC column for the quantification of oryzanol. The column used was a Zorbax eclipse plus $\mathrm{C}_{18}(4.6 \times$ $250 \mathrm{~mm}, 5 \mu \mathrm{m})$. The mobile phase was $\mathrm{ACN}$ : $\mathrm{MeOH}$ : IPA in the ratio 55:35:10 respectively, which had a run time of 25 min with a flow rate of $1.2 \mathrm{~mL} /$ min. The oryzanol content was detected at a wave length of $325 \mathrm{~nm}$ using a Diode array (DAD) detector by Agilent technologies and it was quantified according to the retention time and peak area/height of a standard sample.

\subsection{Statistical analysis}

Each value is the mean of three repetitions. Standard deviation was applied using Microsoft excel software. Sigma stat 3.5 versions were used for analyzing all the experimental data and for finding the regression equation and correlation coefficient.

\section{RESULTS AND DISCUSSION}

Sunflower and safflower oil containing rice bran oil in different proportions were analyzed for various physicochemical parameters (Table 1). Initial iodine value and saponification value were 113.16 and 184.11 for sunflower oil and 137.63 and 183.14 for safflower, respectively. After the addition of $20 \%$ PRBO (physically refined rice bran oil) the iodine and saponification values were reduced to 107.91 and 184.65 for sunflower oil and 102.79 and 184.73 for safflower oil, respectively. Refractive index and specific gravity were 1.46 and 0.9102 for pure sunflower oil and 1.470 and 0.9181 for pure safflower oil, respectively. RI, SV, IV and SG of safflower oil were reported at 1.467-1.470, 186$198,135-150$ and $0.922-0.927$, respectively (CAS/ RS 27-1969) and for sunflower oil, these values were reported at 1.467-1.469, 188-194, 110-143 and 0.918-0.923, respectively (CAS/RS 23-1969) while for PRBO these values were reported at

Table 1

Physico-chemical parameters of physically refined rice bran oil and its blends with Sunflower oil and Safflower oil

\begin{tabular}{|c|c|c|c|c|}
\hline Composition & lodine Value & $\begin{array}{c}\text { Saponification } \\
\text { Value }\end{array}$ & $\begin{array}{l}\text { Refractive } \\
\text { Index }\end{array}$ & $\begin{array}{c}\text { Specific } \\
\text { Gravity }\end{array}$ \\
\hline Pure RBO & $101.55 \pm 0.08$ & $184.93 \pm 0.04$ & $1.469 \pm 0.05$ & $0.9144 \pm 0.03$ \\
\hline Pure Sunflower & $113.16 \pm 0.02$ & $184.11 \pm 0.01$ & $1.460 \pm 0.03$ & $0.9102 \pm 0.07$ \\
\hline $\mathrm{SnF}+\mathrm{PRBO}(99+1)$ & $113.16 \pm 0.10$ & $184.18 \pm 0.04$ & $1.460 \pm 0.03$ & $0.9108 \pm 0.03$ \\
\hline $\mathrm{SnF}+\mathrm{PRBO}(98+2)$ & $112.73 \pm 0.04$ & $184.23 \pm 0.03$ & $1.460 \pm 0.02$ & $0.9107 \pm 0.03$ \\
\hline $\mathrm{SnF}+\mathrm{PRBO}(97+3)$ & $112.06 \pm 0.04$ & $184.29 \pm 0.02$ & $1.460 \pm 0.02$ & $0.9110 \pm 0.02$ \\
\hline $\mathrm{SnF}+\mathrm{PRBO}(96+4)$ & $111.32 \pm 0.05$ & $184.36 \pm 0.05$ & $1.461 \pm 0.08$ & $0.9112 \pm 0.04$ \\
\hline $\mathrm{SnF}+\mathrm{PRBO}(95+5)$ & $111.05 \pm 0.05$ & $184.51 \pm 0.02$ & $1.461 \pm 0.06$ & $0.9113 \pm 0.04$ \\
\hline $\mathrm{SnF}+\mathrm{PRBO}(90+10)$ & $109.68 \pm 0.05$ & $184.59 \pm 0.01$ & $1.462 \pm 0.03$ & $0.9117 \pm 0.02$ \\
\hline SnF + PRBO $(80+20)$ & $107.91 \pm 0.04$ & $184.65 \pm 0.07$ & $1.462 \pm 0.05$ & $0.9120 \pm 0.05$ \\
\hline Pure Safflower oil & $137.63 \pm 0.03$ & $183.14 \pm 0.02$ & $1.470 \pm 0.03$ & $0.9181 \pm 0.02$ \\
\hline SAF + PRBO $(99+1)$ & $137.47 \pm 0.05$ & $183.21 \pm 0.07$ & $1.470 \pm 0.05$ & $0.9179 \pm 0.07$ \\
\hline $\mathrm{SAF}+\mathrm{PRBO}(98+2)$ & $137.39 \pm 0.08$ & $183.53 \pm 0.03$ & $1.470 \pm 0.04$ & $0.9175 \pm 0.02$ \\
\hline $\mathrm{SAF}+\mathrm{PRBO}(97+3)$ & $137.32 \pm 0.05$ & $183.79 \pm 0.05$ & $1.470 \pm 0.05$ & $0.9169 \pm 0.07$ \\
\hline $\mathrm{SAF}+\mathrm{PRBO}(96+4)$ & $137.15 \pm 0.06$ & $184.05 \pm 0.04$ & $1.470 \pm 0.02$ & $0.9163 \pm 0.02$ \\
\hline $\mathrm{SAF}+\mathrm{PRBO}(95+5)$ & $137.08 \pm 0.06$ & $184.25 \pm 0.08$ & $1.470 \pm 0.08$ & $0.9160 \pm 0.02$ \\
\hline $\mathrm{SAF}+\mathrm{PRBO}(90+10)$ & $136.93 \pm 0.04$ & $184.61 \pm 0.03$ & $1.470 \pm 0.05$ & $0.9155 \pm 0.08$ \\
\hline $\mathrm{SAF}+\mathrm{PRBO}(80+20)$ & $136.63 \pm 0.08$ & $184.73 \pm 0.04$ & $1.471 \pm 0.02$ & $0.9151 \pm 0.01$ \\
\hline
\end{tabular}


1.460-1.473, 180-195, 90-105 and 0.910-0.920, respectively (CX/FO 05/19/5). Increasing the proportion of physically refined rice bran oil in a blend resulted in decreased specific gravity. At a proportion of $20 \%$ PRBO, the specific gravity of blend (PRBO:SnF) was reduced to 0.9151 while there were no significant changes in the refractive index of the blend. The data in Table 1 reveal that the change in SV, RI and SG values of blended oil after increasing the proportion of PRBO does not reflect a wide range of difference from the values of pure rice bran oil hence these values were not considered as dependent parameters for quantifying PRBO in blended oil when the samples are unknown in nature. However, the range of IV for PRBO, SnF and SAF are significantly different. Increasing the proportion of PRBO from $1-20 \%$ in a blend of PRBO and SnF decreased IV from 113.16 to 107.91, as was expected. Hence IV was considered as a parameter to quantify $\mathrm{PRBO}$ in this blend. In the present case, the standard range of IV of PRBO and SFA and their blends was overlapping and therefore IV was not considered for quantification of PRBO for this blend but it may be considered as a quantifying parameter when the iodine value of safflower oil and PRO is quite different.

The oryzanol presence in rice bran is reported to have functions similar to vitamin $E$ in promoting growth, facilitating capillary growth in the skin, and improving blood circulation along with stimulating hormonal secretion. Pure rice bran oil was analyzed for oryzanol content which was estimated as 13970.9 and 13897.39 ppm (Table 2) by spectrophotometric and HPLC methods, respectively. Rogers et al., (1993) analyzed oryzanol content by HPLC. The determination of oryzanol has been reported using a reverse-phase HPLC without saponification. Four fractions of oryzanol were successfully separated and quantified. (Azrina et al., 2008).

A model chromatogram for the oryzanol determination in rice bran oil by HPLC is shown in Figure 1. The data in Table 2 indicat the difference in oryzanol content of oils and their blends when being subjected to Spectrophotometry and HPLC detection. The HPLC and spectrophotometric estimation of the oryzanol content can quantify PRBO in blended oils even at a level of 1 and $4 \%$, respectively. The spectrophotometric estimation of the oryzanol content at a level of $4 \%$ PRBO in the blends of SnF:PRBO and SAF:PRBO was 644.17 and $412.8 \mathrm{ppm}$, respectively whereas the HPLC estimation of the oryzanol content at the level of $4 \%$ PRBO in the blends of SnF;PRBO and SAF:PRBO was 996.78 and 569.56 ppm, respectively. The data in Table 2 reveal a significant difference in the estimated values of oryzanol content in PRBO and blended oils using both methods. Oryzanol was

Table 2

Quantification of oryzanol content of Physically Refined Rice Bran Oil and its blend with Sunflower oil and Safflower oil

\begin{tabular}{|c|c|c|}
\hline \multirow[b]{2}{*}{ Composition } & \multicolumn{2}{|c|}{ Oryzanol content (ppm) } \\
\hline & $\begin{array}{c}\text { Spectrophotometry } \\
\text { Estimation }\end{array}$ & $\begin{array}{c}\text { HPLC } \\
\text { Estimation }\end{array}$ \\
\hline Pure RBO & $13970.9 \pm 2.43$ & $13897.39 \pm 2.76$ \\
\hline Pure Sunflower & ND & ND \\
\hline SnF + PRBO $(1+99)$ & ND & 169.87 \\
\hline SnF + PRBO (2 + 98) & ND & 356.11 \\
\hline SnF + PRBO $(3+97)$ & ND & 601.27 \\
\hline SnF + PRBO $(96+4)$ & $644.17 \pm 1.61$ & $996.78 \pm 1.43$ \\
\hline SnF + PRBO $(95+5)$ & $907.64 \pm 1.60$ & $1012.31 \pm 1.64$ \\
\hline $\mathrm{SnF}+\mathrm{PRBO}(90+10)$ & $1463.41 \pm 1.76$ & $1561.92 \pm 1.88$ \\
\hline SnF + PRBO $(80+20)$ & $2519.28 \pm 1.27$ & $2602.71 \pm 1.43$ \\
\hline Pure Safflower oil & ND & ND \\
\hline SAF + PRBO $(99+1)$ & ND & $117.85 \pm 2.21$ \\
\hline $\mathrm{SAF}+\mathrm{PRBO}(98+2)$ & ND & $298.72 \pm 1.86$ \\
\hline SAF + PRBO $(97+3)$ & ND & $408.45 \pm 1.14$ \\
\hline SAF + PRBO $(96+4)$ & $412.18 \pm 1.62$ & $569.56 \pm 1.46$ \\
\hline SAF + PRBO $(95+5)$ & $675.93 \pm 1.28$ & $658.73 \pm 1.31$ \\
\hline SAF + PRBO $(90$ + 10) & $1354.11 \pm 1.56$ & $1312.59 \pm 1.39$ \\
\hline SAF + PRBO $(80$ + 20) & $2701.82 \pm 1.35$ & $2729.66 \pm 1.29$ \\
\hline
\end{tabular}

* PRBO - physically refined rice bran oil, SnF - sunflower oil, SAF - safflower oil, ND - Not detected. 


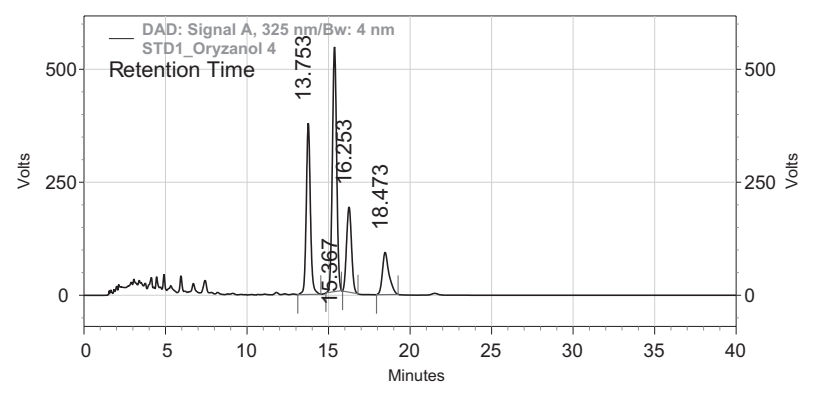

Figure 1

Oryzanol analysis in pure rice bran oil sample using HPLC. 1 = cycloartenyl ferulate; 2 = 24-methylene cycloartanyl ferulate; 3 = campesteryl ferulate; $4=-\beta$-sitosteryl ferulate and cycloartanyl ferulate.

found higher in all the samples when estimated by HPLC which may be due to higher accuracy and sensitivity of the method as compared to the spectrophotometric method.

The data in Table 3 indicate the composition of the major fatty acids present in the oils and their blends. The palmitic acid content of PRBO, SnF and SAF was found to be 19.09, 7.97 and 5.78 respectively. Orthoefer and Smith (1996) reported $18-20 \%$ palmitic acid in rice bran oil, $3-10 \%$ in sunflower oil and $6.8 \%$ in safflower oil. An increase in the proportion of PRBO resulted an increase in the palmitic acid content of the blended oils. The data reflect that there were significant differences in the estimated values of the palmitic acid content of PRBO, SnF and SAF; therefore, the palmitic acid content of the blended oils was considered as an independent parameter for the quantification of PRBO. Physically refined rice bran oil (PRBO), SnF and SAF were found to contain $0.27,0.12$, and $0.15 \%$ myristic acid with $0.21,0.12$ and $0.06 \%$ linolenic acid, respectively. The myristic and linolenic acid contents of both blended oils were found to increase with an increase in the proportion of $\mathrm{PRBO}$ in the blends. According to the results (Table 3), the estimated values of myristic and linolenic acid contents reflect a wide range of differences but due to their diminutive content in blended and poils, these parameters were not considered for PRBO quantification. The oleic and linoleic acid values were found to be $40.44 \%$ and $35.58 \%$ in $\mathrm{PRBO}, 39.95 \%$ and $54.62 \%$ in sunflower oil and $20.01 \%$ and $69.97 \%$ in safflower oil, respectively. All three samples of oil and their blends showed high contents of linoleic acid but the standard range of these fatty acids was found to overlap in pure samples and blended oil which is why these parameters may not be considered for quantifying PRBO in blended oils from unknown samples.

Ultrasonic velocity has been regarded as an important tool for the evaluation of several physical properties of oils and fats. Ultrasonic velocities, relative association, acoustic impedance and compressibility were calculated at 1 and $2 \mathrm{MHz}$ frequencies and at room temperature. The results of compressibility did not show any significant changes when the proportion of rice bran oil was

Table 3

Fatty acid analysis of Pure rice bran oil, pure sunflower oil and their blends

\begin{tabular}{lcccccc}
\hline \multicolumn{1}{c}{ Oils } & Myristic Acid Palmitic Acid & Stearic Acid & Oleic Acid & $\begin{array}{c}\text { Linoleic } \\
\text { Acid }\end{array}$ & $\begin{array}{c}\text { Linolenic } \\
\text { Acid }\end{array}$ \\
\hline PRBO & $0.27 \pm 0.02$ & $19.09 \pm 0.02$ & $3.88 \pm 0.04$ & $40.55 \pm 0.05$ & $35.58 \pm 0.3$ & $0.21 \pm 0.02$ \\
Sunflower Oil & $0.12 \pm 0.03$ & $7.97 \pm 0.04$ & $0.11 \pm 0.07$ & $35.95 \pm 0.03$ & $54.62 \pm 0.2$ & $0.12 \pm 0.01$ \\
SnF + PRBO $(99+1)$ & $0.13 \pm 0.01$ & $8.69 \pm 0.07$ & $0.71 \pm 0.06$ & $37.43 \pm 0.06$ & $54.38 \pm 0.2$ & $0.13 \pm 0.02$ \\
SnF + PRBO $(98+2)$ & $0.13 \pm 0.03$ & $8.78 \pm 0.05$ & $0.94 \pm 0.02$ & $37.88 \pm 0.03$ & $54.14 \pm 0.2$ & $0.14 \pm 0.04$ \\
SnF + PRBO $(97+3)$ & $0.15 \pm 0.02$ & $8.27 \pm 0.02$ & $1.05 \pm 0.07$ & $38.57 \pm 0.02$ & $53.87 \pm 0.5$ & $0.13 \pm 0.06$ \\
SnF + PRBO $(96+4)$ & $0.16 \pm 0.01$ & $9.02 \pm 0.08$ & $1.12 \pm 0.04$ & $39.77 \pm 0.08$ & $53.82 \pm 0.2$ & $0.14 \pm 0.02$ \\
SnF + PRBO $(95+5)$ & $0.17 \pm 0.01$ & $9.51 \pm 0.04$ & $1.23 \pm 0.03$ & $41.31 \pm 0.08$ & $53.45 \pm 0.2$ & $0.16 \pm 0.06$ \\
SnF + PRBO $(90+10)$ & $0.17 \pm 0.02$ & $9.95 \pm 0.07$ & $1.88 \pm 0.06$ & $41.75 \pm 0.05$ & $52.58 \pm 0.6$ & $0.19 \pm 0.01$ \\
SnF + PRBO $(80+20)$ & $0.19 \pm 0.01$ & $10.41 \pm 0.03$ & $2.31 \pm 0.03$ & $42.05 \pm 0.02$ & $50.65 \pm 0.3$ & $0.19 \pm 0.02$ \\
Safflower oil & $0.15 \pm 0.06$ & $5.78 \pm 0.02$ & $1.04 \pm 0.04$ & $20.01 \pm 0.06$ & $69.97 \pm 0.4$ & $0.06 \pm 0.03$ \\
SFO + PRBO $(99+1)$ & $0.17 \pm 0.07$ & $5.79 \pm 0.07$ & $1.19 \pm 0.05$ & $20.78 \pm 0.03$ & $69.41 \pm 0.4$ & $0.07 \pm 0.06$ \\
SFO + PRBO $(98+2)$ & $0.17 \pm 0.04$ & $6.12 \pm 0.03$ & $1.26 \pm 0.02$ & $20.99 \pm 0.02$ & $69.06 \pm 0.3$ & $0.09 \pm 0.03$ \\
SFO + PRBO $(97+3)$ & $0.19 \pm 0.05$ & $6.25 \pm 0.03$ & $1.37 \pm 0.07$ & $21.32 \pm 0.08$ & $68.94 \pm 0.5$ & $0.08 \pm 0.07$ \\
SFO + PRBO $(96+4)$ & $0.20 \pm 0.03$ & $6.34 \pm 0.02$ & $1.45 \pm 0.07$ & $21.83 \pm 0.03$ & $68.26 \pm 0.6$ & $0.11 \pm 0.03$ \\
SFO + PRBO $(95+5)$ & $0.22 \pm 0.01$ & $6.66 \pm 0.08$ & $1.55 \pm 0.05$ & $22.08 \pm 0.04$ & $68.09 \pm 0.3$ & $0.12 \pm 0.07$ \\
SFO + PRBO $(90+10)$ & $0.25 \pm 0.07$ & $6.89 \pm 0.07$ & $1.83 \pm 0.03$ & $22.61 \pm 0.02$ & $66.57 \pm 0.7$ & $0.13 \pm 0.05$ \\
SFO + PRBO $(80+20)$ & $0.29 \pm 0.04$ & $7.52 \pm 0.02$ & $2.03 \pm 0.04$ & $23.15 \pm 0.05$ & $64.12 \pm 0.3$ & $0.14 \pm 0.03$ \\
\hline
\end{tabular}

PRBO - Physically refined rice bran oil, SnF - Sunflower oil, SAF - Safflower oil. 
increased in the blends. The experimental values of ultrasonic velocities were found to be 1450 and 690 in pure rice bran oil, 1441 and 731 in pure sunflower oil and 1426 and 798, in safflower oil at 1 and 2 $\mathrm{MHz}$, respectively (Table 4).

The values of ultrasonic velocities, relative association and acoustic impedance reflected a significant, distinguished change at a frequency of $2 \mathrm{MHz}$ in pure oils and their blends. Ultrasonic velocity at $2 \mathrm{MHz}$ of a blend containing $1 \%$ PRBO and $99 \%$ sunflower oil was 728 which decreased to 720 when the proportion of PRBO in the blend was increased to $20 \%$. Similarly for a blend containing $1 \%$ PRBO and $99 \%$ safflower oil, the ultrasonic velocity was 795 at $2 \mathrm{MHz}$ which decreased to 783 when the proportion of PRBO was increased to $20 \%$ in the blend. The values of acoustic impedence reflected a noticeable increase from 661.68 to 672.56 in the blend of 1:99 (PRBO:SnF) when the proportion of PRBO was increased to $20 \%$. A Similar trend for acoustic impedance was noted for blends of PRBO and SFA. The values of relative association at $2 \mathrm{MHz}$ showed a decrease from 0.139 to 0.1030 when the proportion of PRBO was increased to $20 \%$. As the proportion of PRBO in the blend increased, the ultrasonic velocity and relative association decreased whereas acoustic impedance was increased. The decrease in ultrasonic velocity with the increase in proportion of PRBO in a blend may be due to the higher specific gravity of PRBO due to which the densities of blended oils increased. The values of ultrasonic velocities, acoustic impedance and relative association show a significant difference (Table 4) in pure oils and their blends and in this context, ultrasonic velocities, acoustic impedance and relative association at $2 \mathrm{MHz}$ may be considered independent quantifying parameters in an estimation of PRBO contents. However, a further study pertaining to this aspect is required in order for it to be explored in depth.

With the aim of using all the mentioned data with significant value changes, these data were used for the quantification of pure rice bran oil in the blended oils (PRBO:SnF and PRBO:SFA) under study by subjecting the data to linear regression. Sharma et al., (1999) also quantified individual oils in a mixture of groundnut-palm and groundnut-coconut on the basis of similar computed linear regression equations. Regression analysis deals with situations where a variation of one variable is dependent on the variation of a second variable. Regression may be positive or negative depending upon the orientation of the line $(Y=b X+C)$ with respect to the axis. The ultrasonic velocity, relative association and acoustic impedance at $2 \mathrm{MHz}$, for oryzanol content, palmitic acid and iodine value were selected and were plotted as dependent parameters on the $\mathrm{X}$-axis and the percent proportion of PRBO in the blends was plotted as an independent parameter on

Table 4

Ultrasonic velocities, relative association and acoustic impedances of physically refined rice bran oil, sunflower oil, safflower oil and their blends at different frequencies

\begin{tabular}{lcccccc}
\hline \multirow{2}{*}{ Constituents of blends } & \multicolumn{2}{c}{ Velocity } & \multicolumn{2}{c}{ Ra } & Z \\
\cline { 2 - 6 } & Fr-1(MH) & Fr-2(MH) & F1 & F2 & F1 & F2 \\
\hline PRBO & 1450 & 690 & 0.0822 & 0.0996 & 1331.12 & 746.33 \\
Sunflower oil & 1441 & 731 & 0.0824 & 0.1039 & 1324.28 & 661.68 \\
SnF + PRBO $(99+1)$ & 1442 & 728 & 0.0824 & 0.1039 & 1325.20 & 661.68 \\
SnF + PRBO $(98+2)$ & 1442 & 727 & 0.0824 & 0.1038 & 1325.20 & 662.60 \\
SnF + PRBO $(97+3)$ & 1442 & 725 & 0.0824 & 0.1038 & 1325.20 & 662.60 \\
SnF + PRBO $(96+4)$ & 1443 & 724 & 0.0824 & 0.1038 & 1326.12 & 663.52 \\
SnF + PRBO $(95+5)$ & 1443 & 723 & 0.0824 & 0.1037 & 1326.12 & 664.44 \\
SnF + PRBO $(90+10)$ & 1446 & 721 & 0.0823 & 0.1035 & 1328.87 & 669.03 \\
SnF + PRBO $(80+20)$ & 1450 & 720 & 0.0822 & 0.1030 & 1330.11 & 672.56 \\
Pure Safflower oil & 1426 & 798 & 0.0829 & 0.1012 & 1313.35 & 721.14 \\
SAF + PRBO $(99+1)$ & 1426 & 795 & 0.0829 & 0.1012 & 1313.35 & 722.06 \\
SAF + PRBO $(98+2)$ & 1427 & 794 & 0.0829 & 0.1011 & 1314.27 & 722.98 \\
SAF + PRBO $(97+3)$ & 1429 & 792 & 0.0828 & 0.1011 & 1316.11 & 723.91 \\
SAF + PRBO $(96+4)$ & 1432 & 790 & 0.0828 & 0.1010 & 1318.87 & 726.67 \\
SAF + PRBO $(95+5)$ & 1433 & 789 & 0.0828 & 0.1009 & 1319.79 & 729.43 \\
SAF + PRBO $(90+10)$ & 1437 & 786 & 0.0827 & 0.1007 & 1321.82 & 730.59 \\
SAF + PRBO $(80+20)$ & 1442 & 783 & 0.0825 & 0.1004 & 1325.69 & 733.26 \\
\hline PRBO - physically refined rice bran + oil, SnF - sunflower oil, SAF - safflower oil. & &
\end{tabular}

PRBO - physically refined rice bran oil, $\mathrm{SnF}$ - sunflower oil, SAF - safflower oil. 
Y-axis. The resulting data gave the correlation coefficient $\left(R^{2}\right)$ of $0.753,0.992$, and 0.964 for the ultrasonic velocity, relative association and acoustic impedance of the PRBO and SnF blend and 0.864, $0.964 \& 0.797$ for blends containing PRBO and SFA at $2 \mathrm{MHz}$, respectively (Table 5 ). The correlation coefficient $\left(R^{2}\right)$ for the oryzanol content in blends containing PRBO, SnF and PRBO, SFA was found to be 0.959 and 0.999 , respectively. The $R^{2}$ value for the palmitic acid content of the blends containing, PRBO and SnF, and PRBO and SAF was 0.767 and 0.872 , respectively (Table 5 ) whereas $R^{2}$ values were 0.933 and 0.910 , respectively when blended oils were compared to iodine value. The data revealed that the quality parameters, except palmitic acid content for a blend containing PRBO and SnF, can be considered for quantification of PRBO by using the corresponding equation (Table 5).

\section{CONCLUSION}

The blended oils containing different proportions of physically refined rice bran oil with sunflower and safflower oil were analyzed for their physicochemical properties. By increasing the proportion of PRBO in a blend, significant changes were found in ultrasonic velocity, relative association and acoustic impedance at $2 \mathrm{MHz}$, iodine value, palmitic acid content, and oryzanol content. SV, RI and SG values were not considered as dependent parameters for quantifying PRBO in blended oil whereas the range of IV for $\mathrm{PRBO}, \mathrm{SnF}$ and SAF were significantly different and therefore IV can be used as an indicator for the quantification of PRBO in a blend. The ultrasonic velocity at $2 \mathrm{MHz}$ of a blend containing 1\% PRBO and $99 \%$ sunflower oil was 728 which decreased to 720 when the proportion of PRBO in the blend was increased to $20 \%$, indicating the suitability of the method. The oryzanol content in rice bran oil may be considered as the best indicator to quantify the proportion of rice bran oil. The study revealed that regression equations based on the oryzanol content, palmitic acid composition, ultrasonic velocity, relative association, acoustic impedance, and iodine value can be further used for the quantification of rice bran oil in blended oils. However, a future study pertaining to the quantification of individual oils by implementing ultrasonic velocities, acoustic impedance and relative association is necessary for these variables to be explored in depth.

\section{REFERENCES}

Adhikari S, and Adhikari J. 1992. Methods for the detection/estimation of admixed vegetable oils. J. Oil Technol. Assoc. India 24, 39-43.

AOCS. 2004. Official methods of analysis. 5th ed. American oil chemist's society Champaign, Illinois, Washington DC.

Azrina A, Maznah I and Azizah AH. 2008. Extraction and Determination of Oryzanol in Rice Bran of Mixed Herbarium UKMB; AZ 6807:MR 185, AZ 6808: MR 211, AZ6809: MR 29. ASEAN Food J. 15, 89-96.

CAC/RS 27-1969, 1970. International standard for edible safflower seed oil in Codex Alimentarius Commission. Joint Food and Agriculture Organization/World Health Organization of the United Nations, Rome, p13.

CAC/RS 23-1969, 1970. International standard for edible sunflower seed oil in Codex Alimentarius Commission. Joint FAO/WHO Food Standards Programme, (Accession No: 111882), Rome, p 22.

CD13CS-11 in AOCS. 2004. Official methods of analysis. 5th ed. American oil chemist's society Champaign, Illinois, Washington DC.

Crick DC, Nwokolo EN, Sim JS. 1988. Effect of blending dietary oils on grows performance, total and individual fatty acids absorption by the growing chick. Nutr. Res. 8, 643-51.

Table 5

Regression equations and correlation coefficients of blended oils

\begin{tabular}{|c|c|c|c|c|}
\hline Constituents & $X$ - axis & Y-axis & $\begin{array}{c}\text { Equation } \\
Y=b X+C\end{array}$ & $\mathbf{R}^{2}$ \\
\hline PRBO and SnF blends & $\%$ PRBO in blended oil & Oryzanol content & $Y=122.151 X+257.742^{*}$ & 0.959 \\
\hline PRBO and SnF blends & $\%$ PRBO in blended oil & Palmitic acid $\left(\mathrm{C}_{16}\right)$ content & $Y=0.0952 X+8.660^{* *}$ & 0.767 \\
\hline PRBO and SnF blends & $\%$ PRBO in blended oil & Ultrasonic velocity at $2 \mathrm{MZ}$ & $Y=-0.384 X+726.468^{*}$ & 0.753 \\
\hline PRBO and SnF blends & $\%$ PRBO in blended oil & Relative association at $2 \mathrm{MZ}$ & $Y=-0.0000461 X+0.104^{*}$ & 0.992 \\
\hline PRBO and SnF blends & $\%$ PRBO in blended oil & Acoustic impedence $(\mathrm{Z})$ at $2 \mathrm{MZ}$ & $Y=0.596 X+661.377^{*}$ & 0.964 \\
\hline PRBO and SnF blends & $\%$ PRBO in blended oil & lodine Value & $Y=-0.265 X+112.836^{*}$ & 0.933 \\
\hline PRBO and SAF blends & $\%$ PRBO in blended oil & Oryzanol content & $Y=135.657 X+1.284^{*}$ & 0.999 \\
\hline PRBO and SAF blends & $\%$ PRBO in blended oil & Palmitic acid $\left(\mathrm{C}_{16}\right)$ content & $Y=0.0906 \times+5.872^{* *}$ & 0.872 \\
\hline PRBO and SAF blends & $\%$ PRBO in blended oil & Ultrasonic velocity at $2 \mathrm{MZ}$ & $Y=-0.601 \times+793.718^{*}$ & 0.864 \\
\hline PRBO and SAF blends & $\%$ PRBO in blended oil & Relative association at $2 \mathrm{MZ}$ & $Y=-0.0000419 \times+0.10^{*}$ & 0.964 \\
\hline PRBO and SAF blends & $\%$ PRBO in blended oil & Acoustic impedence (Z) at $2 \mathrm{MZ}$ & $Y=0.609 \times+722.789^{*}$ & 0.797 \\
\hline
\end{tabular}

${ }^{* *}$ Regression equation is applicable at or above the $20 \%$ level of PRBO in blended oil.

${ }^{*}$ Regression equation is applicable at or above the $1 \%$ level of PRBO in blend

SnF Sunflower oil: SAF Safflower oil: PRBO Physically refined rice bran oil. 
CX/FO 05/19/5 in Codex Alimentarius Commission. 2005. Draft amendments to the standards for vegetable oil, Annex 1, Joint FAO/WHO Food Standards Programme Codex Committee On Fats And Oils Nineteenth Session London, United Kingdom.

Datta SK. 1981. Determination of rapeseed oil in mustard oil from the critical solution temperature. J. Assoc. Public Analysts 19, 127-129.

Frankel EN and Huang SW. 1994. Improving the oxidative stability of polyunsaturated vegetable oils by blending with high-oleic sunflower oil. J. Am. Oil Chem. Soc.,71, 255-259.

Handoo SK, Gupta S, Agrawal TN. 1992. Properties of groundnut and cotton seed oil blends. J. Oil Technol. India 24: 83-87.

IICT. 2008. Processing and analytical methodologies of oils and fats. Centre for Lipid Research, Indian Institute of Chemical Technology, Hyderabad, pp 10-11.

Mehta P, Patil A, Bujata H. 1986. Assessment of suitability of various oil blends for culinary purpose. Indian J. Nutr. Diet., 23, 126-131.

Mehra R and Israni R. 1999. Thermodynamic parameters of multicomponent liquid mixtures and their variation with temperature from ultrasonic and density measurements. International conference and exhibition on ultrasonics (ICEU) New Delhi.

Orthoefer FT and Smith J. 1996. Rice bran oil and sunflower oil. In Bailey's Industrial oil and fat products (Ed by Hui, Y.H.), 5th edition, vol. 2, John Wiley and sons Inc. New York, 393-410, 411-456.
Rogers EJ, Rice SM, Nicolosi RJ, Carpenter DR, McClelland CA and Romanczyk Jr LJ. 1993. Identification and quantitation of $\gamma$-oryzanol components and simultaneous assessment of tocols in rice bran oil. J. Am. Oil Chem. Soc. 70, 301-307.

Sharma HK, Singhal RS and Kulkarni PR. 1996. Studies on deep fat frying using blended oils and potato chips. J. Food Lipids, 3, 155-159.

Sharma HK, Singhal RS, Kulkarni PR and Gholap AS. 1999. Detection of oil blends. Nahrung 43, 51-53.

Sharma HK, Kaur B, Sarkar B and Singh C. 2006. Thermal behaviour of pure rice bran oil, sunflower oil and their model blends during deep fat frying. Grasas Aceites 57, 376-381.

Seetharamaiah GS and Prabhakar JV. 1986. Oryzanol content of Indian rice bran oil and its extraction from soap stock. J. Food Sci. Technol. 23, 270-272.

Shiela PM, Sreerama YN, Gopala-Krishna AG. 2004. Storage stability evaluation of some packed vegetable oil blends. J. Am. Oil Chem. Soc. 81, 1125-1129

Susheelamma NS, Asha MR, Ravi R, Kumar AKV. 2002. Comparative studies on physical properties of vegetable oils and their blends after frying. J. Food Lipids 9, 259-276.

Xu Z and Godber JS. 1999. Purification and identification of components of $\gamma$-oryzanol in rice bran oil. J. Agric Food Chem. 47, 2724-2728. 